\title{
CARTA DE LOS DIRECTORES
}

\section{Vol 3. Número 2 (2017)}

Puntual con su compromiso semestral con la comunidad científica y jurídica, la revista Ius et Scientia presenta el segundo número del tercer volumen correspondiente al año 2017, en el que, previa revisión por pares según el sistema de doble ciego, se han seleccionado ocho artículos de calidad y originalidad contrastada, con temática muy variada, pero que cuentan con la Bioética, el Bioderecho, la Biomedicina, las Nuevas Tecnologías y los Derechos Humanos como factores que integran un común denominador.

La dignidad humana como concepto clave, tanto del Derecho Internacional como del Derecho Humanitario Internacional, es el principal objeto de estudio por parte de Vicky Tzatzaki en su estudio a propósito de un derecho humano tan esencial, y a la vez tan básico para la proteger y garantizar la vida humana, como el derecho al agua. En este sentido, la autora analiza las implicaciones y la repercussion teórica y práctica que ha tenido, desde su aprobación en 2002 hasta el presente, la Observación general número 15 sobre el Derecho al agua por el Comité de Derechos Económicos, Sociales y Culturales de las Naciones Unidas, de acuerdo con la cual, a disponer de agua suficiente, salubre, aceptable, accesible y asequible para el uso personal y doméstico constituyen requisitos necesarios para el disfrute de este derecho humano vital, en el que también debe incluirse la dignidad humana como conditio sine qua non del mismo.

La dicotomía ético-jurídica entre el derecho a la salud y el derecho a la intimidad en el ámbito deportivo conforma el marco que abarca el estudio de la Dra. Elena Atienza Macías en relación con el pasaporte biológico. La implantación de los controles antidopaje en las competiciones deportivas en aras de la salud y de la garantía del juego limpio (fair play) ha suscitado en los últimos años un desarrollo normativo en materia de salud deportiva, una mayor presencia y vigilancia por parte de las instituciones 
públicas, y un importante grado de sensibilización social. A este respecto, se pregunta la autora si, ante este panorama normativo, los procedimientos que se han establecido y la práctica de los controles, son respetuosos y si contemplan el marco más general referido a la protección de derechos fundamentales que se consagran tanto en las constituciones de los países miembros de la Unión Europea, como en la Carta Europea de Derechos.

La exploración de datos de información biométrica en el campo de la estadística y de las ciencias de la computación, y su relación con el ámbito de la vida privada y de la protección de datos constituye el tema de investigación del artículo colectivo escrito por Crystalie Bourcha, Maria-Louiza Deftou y la Dra. Anthi Koskina. A propósito de esta técnica de exploración y rastreo de datos privados con supuestos fines científicos, sanitarios o de seguridad pública, se ha suscitado un interesante debate teórico a raíz de algunas sentencias recientemente dictadas recientemente por el Tribunal de Justicia de la Unión Europea, de acuerdo con el concepto de intimidad consagrado en el Convenio Europeo de Derechos Humanos.

El avance de las técnicas biomédicas de monitarización y diagnóstico genético preimplantacional han abierto el debate en torno a la eugenesia y la manipulación genética con fines terapéuticos o de perfeccionamiento de la raza humana que plantea hoy la doctrina transhumanista que pretende dar por superados el paradigma humanista y el Proyecto de la Modernidad heredados de la Ilustración. En su artículo sobre la selección de sexo en fase embrionaria, el Dr. Joaquín Jiménez González hace un balance general de este dilema bioético y biojurídico que actualiza el status quaestionis de este debate en términos éticos, científicos y jurídicos.

En línea de continuidad con las Nuevas Tecnologías aplicadas a las influyentes redes sociales, Patricia Craviotto Valle dedica su artículo a plantear en términos éticojurídicos el debate surgido en torno a la legítima decisión de la maternidad tardía, como opción libre de la futura madre, y la tergiversación que de esta elección se hace por parte de sus detractores en las redes sociales, especialmente entre cibernautas españoles.

En relación con uno de los factores que más ha contribuido a poner de manifiesto el cambio de paradigma ético-político en lo que Ulrich Beck ha denominado 
"la metamorfosis del mundo", Simona Fanni y el Dr. Ernani Contipelli, abordan la interacción entre la teoría de la adaptación humana al cambio climático desde una perspectiva bioética internacional y biojurídica. En este sentido, ambos autores destacan una cuestión novedosa de especial relevancia por sus implicaciones bioético y biojurídicas, como es la edición genética con fines terapéuticos tanto en el ámbito de las nuevas tecnologías de la medicina genética como en el ámbito de la epigenética.

En conexión con los avances científicos realizados en el campo de la experimentación biológica, el Dr. Saad Bentaouet estudia los riesgos y las amenazas que nos plantea la guerra biológica por el uso premeditado e ilimitado de microorganismos, y toxinas, generalmente de origen microbiano, vegetal o animal, para producir enfermedades y muertes entre humanos, ganado y cultivos, y cuyo uso indiscriminado han sido preferentemente realizado por los grupos terroristas en nuestro tiempo como estrategia para desestabilizar y doblegar a la sociedad civil, dañar la economía y atentar contra la salud pública.

A propósito de la seguridad de la sociedad internacional y las catástrofes humanitarias, Andrés Bautista-Hernáez, realiza un estudio sobre los mecanismos de gestión de catástrofes coordinados y efectivos no sólo en los ámbitos local, regional o nacional, sino también y más importante a nivel internacional. En este sentido, en este último artículo se valora en particular el papel fundamental que realiza la Organización de Naciones Unidas en materia de catástrofes en su doble aspecto el institucional y el normativo.

El lector fiel a Ius et Scientia comprobará que los contenidos del presente número son originales, plurales y diversos, atendiendo a nuestra vocación de ofrecer a la comunidad científica y jurídica temas de reflexión novedosos y de interés común en materia de Biomedicina, Biogenética y Bioderecho con objeto de contribuir al debate en materia de protección y garantía de los derechos humanos en el ámbito del Derecho Internacional, y de los derechos y libertades fundamentales en el marco del Estado de Derecho. 